\title{
Design and Analysis of a Separator for Aluminium Dust Particle Collection
}

\author{
Jia Hao $\operatorname{Tan}^{1}$, Douglas Kum Tien Tong ${ }^{1, *}$, and Edwin Chin Yau Chung ${ }^{2}$ \\ ${ }^{1}$ School of Computer Science and Engineering, Faculty of Innovation and Technology, Taylor's \\ University, 1, Jalan Taylors, 47500 Subang Jaya, Selangor, Malaysia \\ ${ }^{2}$ Research \& Enterprise Department, Taylor's University, 1, Jalan Taylors, 47500 Subang Jaya, \\ Selangor, Malaysia
}

\begin{abstract}
Cyclone separators are considered one of the most common and widely used method of separating solid particles from fluids. The focus of this paper was to design a separator that could effectively improve the air quality of an industrial working environment by considering factors such as the nature of the particles and the restrictions on the device such as size and operating condition. To do so, a sample of the dust sample was studied to determine the characteristics of the aluminum dust. An initial separator model which satisfied the separation condition was developed, and a second model was developed with the goal of optimizing and reducing the overall size of the separator. All models developed were subjected to CFD simulations to analyze the flow patterns, separation rate at various particle diameters as well as comparing against the theoretical predicted values. The simulation results showed how the change in various parameters improved the separation efficiency. The total height of the model was approximately $20 \%$ smaller than the initial proposed design to fit into the manufacturer's workbench while the separation efficiencies improved by an average of $5 \%$ to $10 \%$ across various particle sizes. The results obtained indicated that the efficiency of the particle collection is dependent on the area of the barrel inlet of the separator and the depth of the vortex finder.
\end{abstract}

\section{Introduction and Background}

During manufacturing processes such as molding, forging or casting, flashes are typically left attached to the end product as excess, and post production processes would be needed to ensure that these flashes are removed to ensure that the surface of the finished product is smooth and in accordance with the proposed design. To accomplish this, various tools are used depending on the size and surface on which the flash is formed, one of which is the pneumatic file. While the use of such tools can remove the flashes efficiently, it also causes the working environment to become dust laden and harmful to the health of the workers. A diecasting manufacturer had a high employee turnover rate due to this issue despite the workers being required to wear masks through the working process due to the aluminum dust produced.

\footnotetext{
* Corresponding author: douglaskumtien.tong@taylor.edu.my
} 
In order to provide a more conducive work environment the aluminum dust must be removed. A cyclone separator was considered suitable for this purpose. A cyclone separator is commonly used as the primary separator device during manufacturing process as it is able to separate particulates from fluid effectively while the device itself can be easily manufactured and maintained and considerably cheap [1] as compared to other separation devices such as electrostatic precipitator and scrubbers. The separation principle of the cyclone is based on the centrifugal forces generated by the differences in density of the particles entering the device. Despite that, the vortex generated is complex and highly turbulent. Therefore, it is important to understand how the vortex is generated and how is it affected by the parameters of the separator.

The design procedure for the cyclone considered in this study is based on the work by Copper and Alley [2], which in turn is based on the foundation laid by Lapple back is the 1950's [2]. These equations, which were subsequently used widely to design cyclone separators are known as the classical cyclone design [2]. They do have restrictions as the designing process requires prerequisite information that is crucial to the design of the cyclone separator and the results from the equations were approximately $10 \%$ differed from the results obtained from CFD simulations. Nevertheless, these equations were useful as it predicts the approximate size and operating condition of the separator.

Work by Tan [3] showed the effects of the differences in the depth and diameter of the vortex finder had on the length of the vortex generated of cyclone separator at different flow rates. The increase in depth and reduction in the diameter of the vortex finder would generate a greater vortex length [3]. This finding is important as the correlation between the vortex length and the pressure drop was established i.e. that the pressure drop reduces with increase in vortex length as the flow rate increases. The reduction in pressure drop within the system indicates that less power is required to generate the pressure difference between the inlet and outlet of the separator required to generate a vortex length that is sufficient for the separator at a certain flow rate.

The objective of this study is to design an optimized cyclone separator capable of separating aluminum dust from the working environment effectively while ensuring that the size of the cyclone separator is small enough to be retrofitted into the current workbench used at the manufacturer.

\section{Methodology}

This project consists of 3 different stages i.e. the validation stage, the designing stage and the modification stage. At each stage, the separation efficiency is the primary concern about the effectiveness of the model. However, the flow pattern and the vortex generated within the cyclone is complex and they are easily affected by the design and operating conditions of the separator. Theoretical equations developed by previous researchers were implemented to develop the initial model and results obtained from a CFD model generated on ANSYS software was compared with the initial model. This allowed identification of any model errors which could be rectified before commencing with prototype design. Once the model was verified, several modifications were implemented to the model with the goal of reducing the height of the separator while maintaining the separation efficiency and flow rate. For simulation the material selected for separation was ash-solid and the density was set accordingly. The reason for this setting was due to the nature of the dust sample provided by the manufacturer. A sieve shaker was used to determine the particle size distribution of the sample, and the results showed that the sample size ranged from $150 \mu \mathrm{m}$ to $4 \mathrm{~mm}$. As the size of the sample reduces, the shape adopted a more generic characteristic. The smaller dust sample had an irregular sphere surface and the larger pieces were in the form of stripes and chucks. The sample with irregular sphere surface comprised 
approximately $90 \%$ of the dust sample. The sample also contain other particulates such as hair and wood. In order to reduce the complexity of the analysis, the sample was assumed to have perfect sphericity. Ash-solid was the material that most closely resembled the sample material.

\subsection{Model validation}

The initial stage of the design was to compare the model against the theoretical equations. A model developed by Bashir [2] was chosen as the validation model. Based on his findings, the simulations results obtained for the separation efficiency of the separator differed approximately $5 \%$ to $20 \%$ from the theoretical equation developed by Lapple [2]. The model validation is done by reconstructing and verifying his findings and the equations used. The first step was to calculate the operating characteristic of the particle using the theoretical equation based on the specification defined using equations (1), (2) and (3), which were for the cut off diameter, residence time and separation efficiency respectively. The cut off diameter determines the size of the particle that would have a minimum of $50 \%$ separation rate. Table 1 shows the configuration of the model proposed by Bashir [2] and Table 2 is the injection condition. Figure 1 shows the ratio between each parameter to the diameter of the cyclone separator.

$$
\begin{aligned}
& d_{P c}=\left[\frac{q \mu w}{2 \pi N_{q} v_{i}\left(\rho_{v}-\rho_{g}\right)}\right]^{1 / 2} \\
& \Delta t=\frac{\pi D N}{v_{i}} \\
& n_{j}=\frac{1}{1+\left(\frac{d_{w c}}{d_{p_{i}}}\right)^{2}}
\end{aligned}
$$

Table 1. Configuration of the validation model

\begin{tabular}{|l|c|c|}
\hline Parameter & Dimensions & Value (m) \\
\hline Barrel of Cyclone & $\mathrm{D}_{\mathrm{c}}$ & 0.3048 \\
\hline Length of Body & $\mathrm{L}_{\mathrm{c}}$ & 0.6090 \\
\hline Length of Cone & $\mathrm{Z}_{\mathrm{c}}$ & 0.6090 \\
\hline Height of Inlet & $\mathrm{H}_{\mathrm{c}}$ & 0.1524 \\
\hline Width of Inlet & $\mathrm{B}_{\mathrm{c}}$ & 0.0762 \\
\hline Diameter of Vortex Finder & $\mathrm{D}_{\mathrm{e}}$ & 0.1524 \\
\hline Diameter of Dust Outlet & $\mathrm{J}_{\mathrm{c}}$ & 0.0762 \\
\hline Length of Vortex Finder & $\mathrm{S}$ & 0.1905 \\
\hline Length of $\mathrm{S}_{\mathrm{c}}$ & $\mathrm{S}_{\mathrm{c}}$ & 0.0381 \\
\hline
\end{tabular}

Table 2. Injection condition for validation model

\begin{tabular}{|l|c|}
\hline Parameter & Value \\
\hline Particle Speed & $5 \mathrm{~m} / \mathrm{s}$ \\
\hline Flow Rate & $1 \mathrm{e}-20 \mathrm{~kg} / \mathrm{s}$ \\
\hline Particle Density & 1600 \\
\hline
\end{tabular}




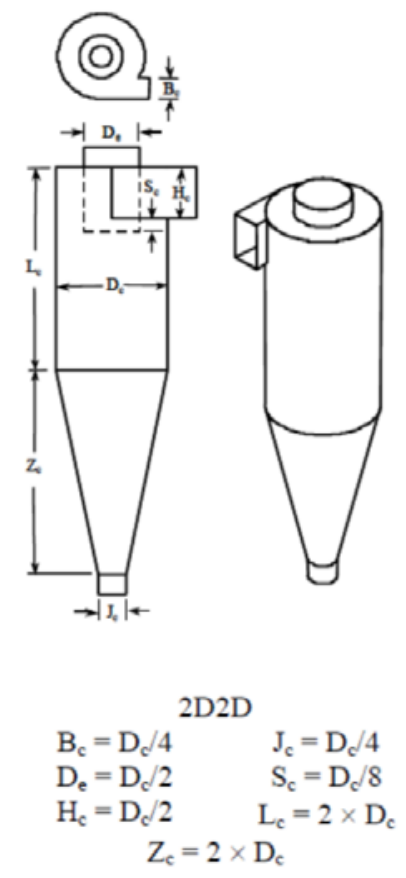

Fig. 1. Dimension design for 2D2D cyclone separator

Figure 2 shows the difference between the predicted and simulated separation efficiency. The data indicated that the results were similar for the majority particle sizes. Although there is a slight difference at particle sizes between $2 \mathrm{e}^{-5} \mathrm{~m}$ to $3 \mathrm{e}^{-5} \mathrm{~m}$, the predicted and simulated results both showed a similar trend i.e. that the separation rate increases as the particle size diameter increases. This is due to the centrifugal force of the particle increases as the size increases.

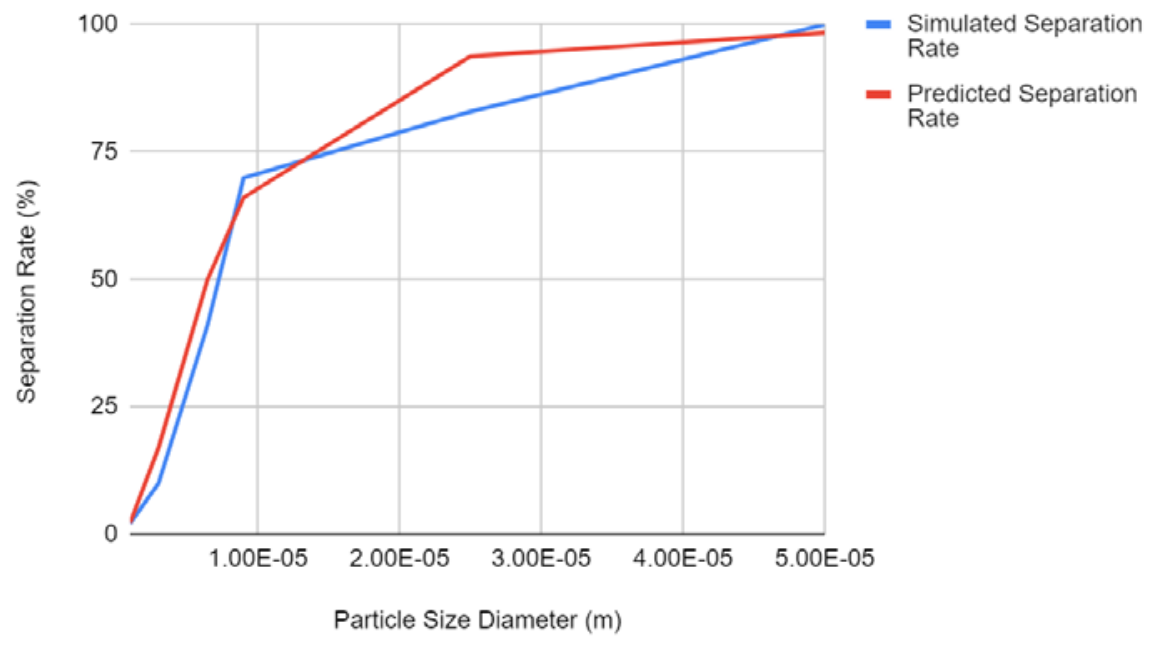

Fig. 2. Separation rate comparison 


\subsection{Design stage}

Once the simulation was carried out and the base model was validated, the next step would be to design the desired cyclone. For the design phase, the first step is to identify the parameters, operating condition and space restriction. A dust sample was provided by the manufacturer and this sample was analyzed using the facilities at the Taylor's University Engineering Lab. The dust sample was found to contain aluminum dust, woods chips and hair and it weighed approximately $30.55 \mathrm{~g}$. The density of the particles was determined based on the weight measured and the plastic bag that contained the dust sample folded repeatedly until an approximate cuboid was formed. Figure 3 shows the dust sample that was provided by the manufacturer in a plastic bag. The plastic bag was folded to a cuboid to approximate the volume of the dust. Figures 4 is that of the sieve shaker used to determine the particle size distribution of the dust sample while Figure 5 was the subsequent results. The shape of the larger dust particles was in the form of strips and chucks, whilst the smaller particles were in the shape of irregular spherical pellets. Figure 6 shows the dust sample provided before sieving. Table 3 shows the precondition for separator.

Fig. 3. Dust sample

Fig. 4. Sieve shaker used to determine particle size distribution 
Fig. 5. Particle size distribution results after 10 minutes

Fig. 6. Dust sample provided containing aluminium stripes, chunks and pellets

Table 3. Precondition of the separator

\begin{tabular}{|l|l|}
\hline Parameters & Value \\
\hline Entry velocity & $4.53 \mathrm{~m} / \mathrm{s}$ \\
\hline Weight of Sample & $30.55 \mathrm{~g}$ \\
\hline Volume & $(15.8 \times 2.0 \times 0.8) \mathrm{cm}^{3}$ \\
\hline Particle density & $1208.645 \mathrm{~kg} / \mathrm{m}^{3}$ \\
\hline Smallest particle size estimated & $8 \mathrm{e}^{-6} \mathrm{~m}$ \\
\hline
\end{tabular}

The total height of the device was restricted at $700 \mathrm{~mm}$ as the ideal placement of the device is under the workbench of the workers.

After identifying the precondition, the next step was to select a model type. The Lapple model was selected as it was the most common cyclone model. There are 3 types of Lapple model, 1D3D, 1D2D and 2D2D. The 1D2D model, although an improve version of the other two models, was not considered as the improvement made was to overcome the 'cycling lint' issue, which was irrelevant to the application that is being considered in this project. The 2D2D model was selected to increase the residential time for the particles. Once 2D2D was decided on, the next step was to construct the 3D model of this cyclone and to calculate the parameters of the model using the theoretical equations. 
Once the model was constructed, CFD simulation was performed based on the theoretical values. The validity and accuracy of the model would be determined based on the separation rate of the different particle sizes.

\subsection{Modification stage}

The last stage was to apply modifications to the initial model in order to optimize the operating conditions and simultaneously reduce the length of the cyclone separator. Based on previous researches, several parameters were chosen for modification. Table 4 details the selected parameters and the reasons for selecting said parameter for modification. The injection condition of for the modified model will be maintained the same as the initial model.

Table 4. Parameters selected or modification

\begin{tabular}{|l|l|}
\hline Parameters & Reasoning \\
\hline Width of the inlet & $\begin{array}{l}\text { Increasing the KA ratio, which is the area of the barrel to } \\
\text { the area of the rectangular inlet improves the Maximum } \\
\text { Effective Inlet Velocity (MEIV) of the particles entering } \\
\text { the cyclone separator [4]. The closer the entry velocity } \\
\text { value is to the MEIV, the higher the separation efficiency }\end{array}$ \\
\hline Length of the inlet & $\begin{array}{l}\text { Particles are shown to be more likely separated when the } \\
\text { particles entering at the inlet area closer to the wall of the } \\
\text { barrel. [5] }\end{array}$ \\
\hline Diameter of the vortex finder & $\begin{array}{l}\text { Diameter affects the pressure loss throughout the system } \\
\text { and the separation efficiency. Large area reduces the } \\
\text { pressure loss however the vortex generated would be } \\
\text { larger, separation efficiency would be affected as the } \\
\text { likelihood of particles getting caught in the vortex } \\
\text { increases during the separation process. [6] }\end{array}$ \\
\hline $\begin{array}{l}\text { Total Insertion depth of the vortex } \\
\text { finder }\end{array}$ & $\begin{array}{l}\text { Increasing the total insertion depth could reduce the } \\
\text { pressure drop of the system as the flow rate increases. [7] }\end{array}$ \\
\hline
\end{tabular}

\section{Results and Discussion}

Table 5 shows the results of the validation model in comparison to the theoretical results. Figure 7 shows the results obtained when the validation model was simulated with particles of diameter of $2.50^{-5-} \mathrm{m}$. The predicted efficiency was obtained using equation (3) while the simulated efficiency was obtained using equation (4).

$$
d_{P c}=\left[\frac{\text { Trapped particle-incomplete particle }}{\text { Total particle injected }}\right]^{1 / 2}
$$

Table 5. Results of the validation model

\begin{tabular}{|c|c|c|c|}
\hline $\begin{array}{c}\text { Particle Diameter } \\
(\mathbf{m})\end{array}$ & $\begin{array}{c}\text { Predicted } \\
\text { Efficiency }\end{array}$ & $\begin{array}{c}\text { Simulated } \\
\text { Efficiency }\end{array}$ & $\begin{array}{c}\text { Percentage } \\
\text { Error }\end{array}$ \\
\hline $1.00 \mathrm{e}-6$ & 0.023 & 0.022 & -0.045 \\
\hline $3.00 \mathrm{e}-6$ & 0.17 & 0.1 & -0.41 \\
\hline $6.45 \mathrm{e}-6$ & 0.5 & 0.41 & -0.18 \\
\hline $9.00 \mathrm{e}-6$ & 0.6606 & 0.699 & 0.06 \\
\hline $2.50 \mathrm{e}-5$ & 0.9376 & 0.829 & -0.12 \\
\hline $5.00 \mathrm{e}-5$ & 0.9836 & 1 & 0.02 \\
\hline
\end{tabular}




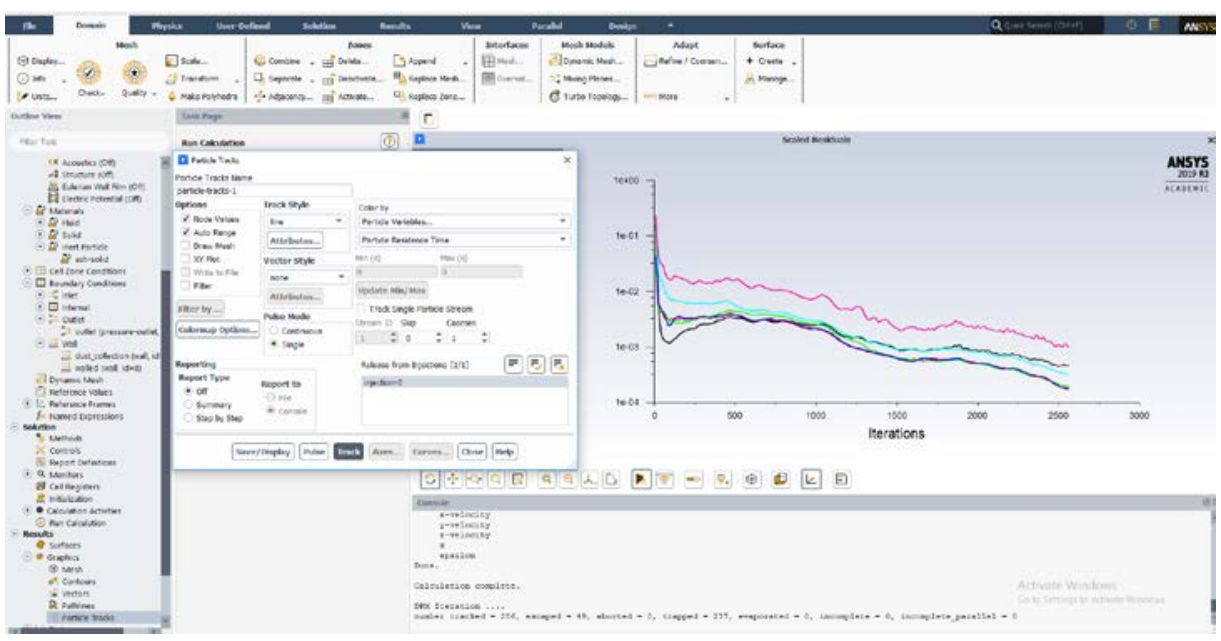

Fig. 7. Simulation results of the validation model with particle diameter of $2.5 \mathrm{e}-5 \mathrm{~m}$

As predicted, there were some discrepancies between predicted and simulated efficiency. However, the validation is considered to be completed and the theoretical results proved to be reliable as the percentage errors were very small (Table 5). The next step was to use the theoretical equation to develop the desired model. Table 6 shows the configuration of the initial model and Table 7 shows the comparison between the separation efficiency predicted and simulated results.

Table 6. Configuration of the initial model

\begin{tabular}{|l|c|c|}
\hline Parameters & Dimensions & Value (m) \\
\hline Barrel of Cyclone & $\mathrm{D}_{\mathrm{c}}$ & 0.175 \\
\hline Length of Body & $\mathrm{L}_{\mathrm{c}}$ & 0.350 \\
\hline Length of Cone & $\mathrm{Z}_{\mathrm{c}}$ & 0.350 \\
\hline Height of Inlet & $\mathrm{H}_{\mathrm{c}}$ & 0.0875 \\
\hline Width of Inlet & $\mathrm{B}_{\mathrm{c}}$ & 0.04375 \\
\hline Diameter of Vortex Finder & $\mathrm{D}_{\mathrm{e}}$ & 0.0875 \\
\hline Diameter of Dust Outlet & $\mathrm{J}_{\mathrm{c}}$ & 0.04375 \\
\hline Length of Vortex Finder & $\mathrm{S}$ & 0.109375 \\
\hline Length of $\mathrm{S}_{\mathrm{c}}$ & $\mathrm{S}_{\mathrm{c}}$ & 0.021875 \\
\hline
\end{tabular}

Table 7. Results of initial model

\begin{tabular}{|c|c|c|c|}
\hline $\begin{array}{c}\text { Particle } \\
\text { Diameter }\end{array}$ & $\begin{array}{c}\text { Predicted } \\
\text { Efficiency }\end{array}$ & $\begin{array}{c}\text { Simulated } \\
\text { Efficiency }\end{array}$ & $\begin{array}{c}\text { Percentage } \\
\text { Error }\end{array}$ \\
\hline $1.00 \mathrm{e}-6$ & 0.028 & 0.029 & 0.035 \\
\hline $3.00 \mathrm{e}-6$ & 0.207 & 0.173 & -0.164 \\
\hline $5.879 \mathrm{e}-6$ & 0.500 & 0.465 & 0.070 \\
\hline $9.00 \mathrm{e}-6$ & 0.701 & 0.725 & 0.034 \\
\hline $2.50 \mathrm{e}-5$ & 0.948 & 1 & 0.055 \\
\hline $5.00 \mathrm{e}-5$ & 0.986 & 1 & 0.014 \\
\hline
\end{tabular}

The modifications made to the initial model are shown in Table 8 and the comparison of the separation efficiencies is shown in Table 9. 
Table 8. Modified parameters

\begin{tabular}{|l|c|c|}
\hline Parameters & Initial Model & Modified Model \\
\hline Width of the inlet & $43.75 \mathrm{~mm}$ & $29.17 \mathrm{~mm}$ \\
\hline Height of the inlet & $87.5 \mathrm{~mm}$ & $140 \mathrm{~mm}$ \\
\hline Diameter of the vortex finder & $87.5 \mathrm{~mm}$ & $70 \mathrm{~mm}$ \\
\hline Total Insertion depth of the vortex finder & $109.375 \mathrm{~mm}$ & $196 \mathrm{~mm}$ \\
\hline
\end{tabular}

The modified width was determined based on equation (5), which is the KA of the separator.

$$
K A=\frac{\pi r^{2}}{W H}
$$

The increase in KA value increases the separation rate of the separator [4]. To increase the value of KA, two options are available i.e. increase the area of barrel or decrease rectangular inlet area. The rectangular inlet area, particularly the width of the inlet was selected as the barrel diameter was crucial to the residence time [5]. Previous study indicated a larger barrel would increase the residence time of the particles in the separator, which increases the likelihood of the particles being separated due to collision with one another during the separation process. However, increasing the diameter of the barrel would increase the volume of the separator significantly, therefore it was left unaffected. The length of the of the height of the inlet was also extended in order to increase the area closer to the wall of the barrel. These two adjustments were related as the increase in inlet area, though increase the separation rate, reduces the MEIV of the particle.

Table 9. Separation efficiency of the cyclone model

\begin{tabular}{|c|c|c|}
\hline Particle Diameter (m) & Initial Model & Modified Model \\
\hline $1.00 \mathrm{e}-6$ & 0.029 & 0.109 \\
\hline $3.00 \mathrm{e}-6$ & 0.173 & 0.211 \\
\hline $5.879 \mathrm{e}-6$ & 0.465 & 0.593 \\
\hline $9.00 \mathrm{e}-6$ & 0.725 & 0.824 \\
\hline $2.50 \mathrm{e}-5$ & 1 & 1 \\
\hline $5.00 \mathrm{e}-5$ & 1 & 1 \\
\hline
\end{tabular}

The other two parameters that were modified were the diameter and insertion depth of the vortex finder. The vortex finder was selected as it is important in controlling the length of the vortex generated and the pressure loss of the system. The diameter and insertion depth of the vortex finder were reduced and increased in order to generate a better vortex length. Reducing the diameter would reduce the pressure and increases the pressure drop across the system. The increase in pressure drop would increase the length of the vortex generated and increases the separation rate, however at the same time increases in pressure drop increases the power consumption.

After completing all simulations, the data were compared. The overall separation of the particles at different diameters improved approximately 5 to $10 \%$ except for the larger particle sizes which were already at maximum efficiency. The main factors which resulted the increase in separation efficiency was due to the velocity and the pressure drop across the system. Remodeling of the inlet dimension would have slightly reduced the velocity of the particles, but this was compensated by the remodeling of the diameter of the vortex finder, which increases the pressure difference between the inlet and outlet, which resulted in increased separation efficiency.

One limitation of this study is that the results were derived from theoretical equations, computer simulations and knowledge obtained from previous researches but without 
conducting any physical experimentation. Further verification of the results would require real life experimentation to better understand the nature of the flow and separation in the cyclone separator. Apart from that, the simulations results could still be further enhanced by increasing the number of variations of the parameters that were selected for modifications to better understand the correlation of the parameters and the separation efficiency.

Figure 8 shows the trajectory and flow of the particles visually from the CFD simulation of the modified model.

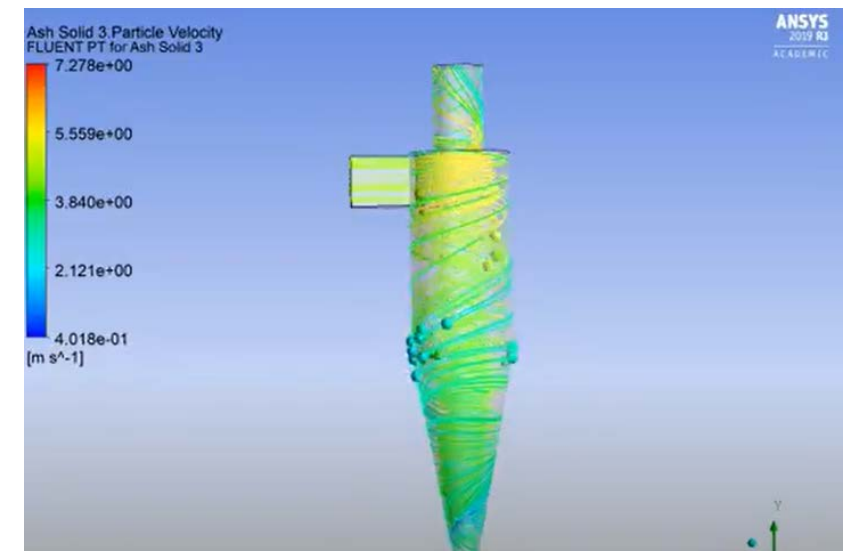

Fig. 8. Trajectory and velocity of the particle on modified model.

\section{Conclusion and Recommendations}

The modified model has shown to be on an average 5\% to $10 \%$ more effective in separating particles of the same diameters compared to the initial model. The modified model has a total height of $20 \%$ shorter than that of the initial model in order to fit into the manufacturer's workbench, while having satisfactory separation efficiency. The pressure drop of the modified model increased slightly in comparison with the initial model, which indicated that the power consumption of the modified system would increase when operating at its optimum condition. Aside from the modifications listed above, there are other alternatives to improve the separation efficiency. One suggestion by [8] would be to include a stainless steel filter to capture any particles that might escape from the vortex finder. Other suggestions such as adding Reduced Pressure Drop Stick (REPDS) with polygon profile [9] and tilting the inlet angle of a rectangular inlet [10] can improve the pressure drop and increase the entry velocity of the particles respectively. Physical experimentation should also be carried out to confirm the results. As the cyclone separator designed was customized to suit the needs of the diecasting manufacturer, customized ducting and retractable stands would also be required for its full functionality if it is to be implemented at the manufacturer's premises.

\section{References}

1. Y. Wang, S. Zhou, S. Zhang. "Analysis of the Combined Cyclone and Filter Cartridge Separator for a Hazardous Materials Rescue Truck" The Second International Conference on Materials Chemistry and Environmental Protection (2018).

2. K. Bashir, "Design and fabrication of cyclone separator," Thesis (2015).

3. F. Tan, I. Karagoz, A. Avci, Chem. Eng. Commun., 203, 1216-1221 (2016) 
4. J. X. Yang, G. G. Sun, Y. M. Zhang, Q. Ma, C. Li, Oil Shale, 34, 155 (2017)

5. L. Liu, H. S. Dou, X. Chen, The Journal of Computational Multiphase Flows, 8, 40-47 (2016)

6. H. Wang, IOP Conf. Ser. Mater. Sci. Eng., 721, 012037 (2020)

7. W. B. Faulkner, B. W. Shaw, Appl. Eng. Agric., 22, 155-161 (2006)

8. M. Sangkhamanee, S. Tekasakul, P. Tekasakul, Y. Otani, Part. Sci. Technol., 29, 345355 (2011)

9. N. Prasanna, R. Prakash, M. Vijayakumar, Int. J. Veh. Struct, Syst., 8, 296-300 (2017)

10. L. V. Sy, Part. Sci. Technol., 35, 555-564 (2016) 